\title{
Editorial
}

Journal of Research in Interprofessional

Practice and

Education

Vol. 7.1

2017

Journal of Research in Interprofessional

Practice and Education (JRIPE)

Vol. 7.1

(c) 2017

Corresponding author: Hassan Soubhi. Email: editor1@jripe.org

\section{Toward an Experiential Approach to Interprofessional Communication}

\author{
Hassan Soubhi, MD, PhD
}

There is a famous quote from the movie Cool Hand Luke [1] when the prison warden says to Luke right after hitting him, "What we've got here is failure to communicate; some men you just can't reach." Aside from the entertaining drama, I keep two implications from this quotation: communication is more than information transfer, it is also about reach; and reach can be costly.

A dictionary definition reveals several meanings for the word "reach": stretch out; touch or grasp by stretching; arrive at; get in contact; and interestingly enough, "succeed in having an effect on" [2]. I lean toward the latter, simply because thinking of communication as exerting an influence offers a better chance of assessing that influence. Our goals must be smart and measurable. They must also consider local contexts.

Communication is central in an interprofessional context. Problems arise when we treat communication mainly as an exchange of information and ignore all the subtle non-verbal signifiers: attitudes, body language, cultural norms, and institutional rules. Shannon and Weaver [3] offered a theory of communication as reliability in encoding and decoding information as a set of symbols. We usually conceive of communication as the transfer of a string of symbols with the assumption that the syntactic rules are known-we get the meaning if we can decode the string. This view is appealing. We see its usefulness in computers as they extend our minds every day. It becomes, however, particularly costly with specialization and the increased division of labour that is necessary for collective works. As it increases productivity, specialization also brings with it elaborate algorithms that only experts know. A higher level of energy must then be spent to encode and decode expert information-a cost that can be prohibitive in an interprofessional context, which calls for speed and efficiency in the integration and transfer of knowledge.

So if interprofessional communication is more than information transfer, and if the division of labour increases both the productivity and the costs of communication, what can we do? How can we better understand interprofessional communication?

First, we need to consider that an effective interprofessional group lowers the costs of communication. The human history of collective work is filled with successive attempts to reduce those costs and coordinate the exchange of energy-an important part of what makes or breaks collective work. For what do groups do in the real world? At a fundamental level, they exchange information and energy. In doing so, they establish connections between agents and objects: the connections can be physical (as in sharing the other end of the rope), symbolic (as in incentives), or mental (as in language and working memories in the brain). Group members not only exchange bits 
2

Editorial

Soubhi

Journal of Research in Interprofessional Practice and Education

Vol. 7.1

2017 of information, they also negotiate meanings, and if they maintain long enough working relationships, they can cultivate an enduring context for new knowledge [4,5].

Second, if as Lawn [6] suggests, we need to review our research agendas for interprofessional education, we surely need to review how we study interprofessional communication. We can then choose Shannon and Weaver's view of communication as the transmission of symbols, or we can choose to view communication through a more elaborate lens, one that considers how we live it every day. Lived experience-an embodied approach-attests to the richness of what and how we communicate. As Kogut and Zander [7] suggest, the word discourse is probably more appropriate than information in this context. It draws attention to the critical role played by language, symbol, and interpretation in the operations that bind group members. There is probably much to gain by using an experiential approach to research in interprofessional communication, one that recognizes that meaning is based on the understanding of experience [8-10]. Knowledge thus acquired cannot be dissociated from the experience of communication, rather than being framed by an abstract theory (mathematical or otherwise). Models of experiential learning and experiential research that combine experience with reflection, discussion, and evaluation of that experience are a case in point [11,12]. The experiential here includes all the basic sensory-motor, emotional, and social experiences available to all human beings, and a balance is nurtured between head and heart, technical skills and insightful compassion, and system design and the ethical dimensions of interprofessional practice $[4,13]$.

The research agenda in interprofessional communication would then expand in subject matter and methodologies (the plural is strongly intended). The subject is indeed complex. Amid the variations in interpersonal styles of communication and ways of transmitting what we know to others, there are also differences in perceptions and how they can affect the participants in a discussion $[14,15]$. This complexity is compounded by the speed of change in technology and how we adapt it to our needs [16], whether in the real world or in a simulated one [17]. Added to this mix is what the concept of a hidden curriculum implies: informal learning in interprofessional education cannot be denied [18], and in the same way that we know more than we can tell [19], we often express more than we can say.

To sum up, healthcare has one specific person-centered goal: solving patients' problems. Communication is central to healthcare. It is more than information transfer. It is also about reach, and reach can be costly. Interprofessional groups have the potential to lessen the cost and create and communicate knowledge with speed and efficiency. They are more likely to do so when they include an awareness of human experience and use an experiential approach to understanding meaning and communication. Otherwise, they are more likely to amplify the consequences of the ongoing specialization and fragmentation of knowledge.

\section{References}

1. ginpole. (2010). Cool Hand Luke. YouTube. (Originally released in 1967) URL: https://www .youtube.com/watch?v=yBBWUZfgRiw . 
3

Editorial

Soubhi
2. Dictionary of the English Language ( $\left.5^{\text {th }} \mathrm{ed}\right)$. (2011). Reach. Boston, MA: Houghton Mifflin Harcourt.

3. Shannon, C.E., \& Weaver, W. (1949). The mathematical theory of communication. Chicago, IL: University of Illinois Press.

4. Soubhi, H., Colet, N.R., Gilbert, J.H.V., Lebel, P., Thivierge, R.L., Hudon, C., \& Fortin, M. (2009). Interprofessional learning in the trenches: Fostering collective capability. Journal of Interprofessional Care, 23(1), 52-57.

5. Wenger, E., McDermott, R., \& Snyder, W.M. (2002). Cultivating communities of practice: A guide to managing knowledge. Boston, Mass.: Harvard Business School Press.

6. Lawn, S. (2016). Moving the Interprofessional education research agenda beyond the limits of evaluating student satisfaction. Journal of Research in Interprofessional Practice and Education, 6(2), 1-11.

7. Kogut, B., \& Zander, U. (1996). What firms do? Coordination,identity, and learning. Organization Science, 7(5), 502-518.

8. Dobie, S. (2007). Reflections on a well traveled path: Self-awareness, mindful practice, and relationship-centered care as foundations for medical education. Academic Medicine, 82(4), 422-427.

9. Ünal, S. (2012). Evaluating the effect of self-awareness and communication techniques on nurses' assertiveness and self-esteem. Contemporary Nurse, 43(1), 90-98.

10. Beebe, S.A., Beebe, S.J., Redmond, M.V., \& Geerinck, T.M. (2004). Interpersonal communication: Relating to others. Toronto, ON: Pearson Education Canada.

11. Henry, J. (1989). Meaning and practice in experiential learning. In S.W.I. McGill (Ed.), Making sense of experiential learning (pp. 29-33). Milton Keynes, UK: Open University Press.

12. Moustakas, C. (1990). Heuristic research: Design, methodology, and applications. London: Sage.

13. Lakoff, G. (1987). Women, fire, and dangerous things: What categories reveal about the mind. Chicago, IL: University of Chicago Press.

14. Buhler, A.V., Coplen, A.E., Davis, S., \& Nijjar, B. (2016). Comparison of Communications Styles Among Students in Allied Health Professions Programs: How Do Our Students Communicate with Other Healthcare Providers? Journal of Research in Interprofessional Practice and Education, 6(2), 1-14.

15. McMillan, C., \& Madill, J. (2016). A cross comparative study to examine beliefs and attitudes regarding food and eating between food and nutrition and social work students. Journal of Research in Interprofessional Practice and Education, 6(2), 1-17.

16. Graves, M. \& Doucet, S. (2016). Factors Affecting Interprofessional Collaboration when Communicating through the use of Information and Communication Technologies: A Literature Review. Journal of Research in Interprofessional Practice and Education, 6(2), 1-33.

17. Davis, D.L., Hercelinskyj, G., \& Jackson, L.M. (2016). Promoting Interprofessional Collaboration: A Pilot Project Using Simulation in the Virtual World of Second Life. Journal of Research in Interprofessional Practice and Education, 6(2), 1-15.

18. Reade, M., Maar, M., Cardinal, N., Boesch, L., Lacarte, S., Rollins, T., \& Jeeves, N. (2016). The impact of hidden curriculum in wilderness-based educational events on interprofessional competencies: A mixed-method study. Journal of Research in Interprofessional Practice and Education, 6(2), 1-16.

19. Polanyi, M. (205). Personal Knowledge. Chicago, IL: The University of Chicago Press.
Journal of Research in Interprofessional Practice and Education

Vol. 7.1

2017 